\title{
Angiotensin II-Induced Tachyphylactic Constrictions in Isolated and Perfused Canine Mesenteric Arteries
}

\author{
Shigetoshi Chiba and Miyoko Tsukada \\ Department of Pharmacology, Shinshu University School of \\ Medicine, Matsumoto 390
}

Chiba, S. and Tsukada, M. Angiotensin II-Induced Tachyphylactic Constrictions in Isolated and Perfused Canine Mesenteric Arteries. Tohoku J. exp. Med., 1986, 150 (4), 417-426 — The stainless steel cannula inserting method was used to investigate the effects of angiotensin II on isolated and perfused dog mesenteric arteries with and without indomethacin treatment, or with and without intraluminal saponin-treatment which removed the endothelium. In non-treated preparations, angiotensin II was intraluminally administered repetitively at 10, 20, 30 or 60 min inervals. Each period of angiotensin II causes tachyphylaxis. The order of degree of tachyphylaxis was $10>20>30>60$ min intervals. Relatively large doses much readily caused tachyphylaxis. Tachyphylaxis was not affected by phentolamine-treatment preparations. In indomethacin $(5 \mathrm{mg})$-treated preparations, the angiotensin II-induced tachyphylaxis was significantly less than that in non-treated ones. In small doses of angiotensin II, tachyphylaxis did not appear in the majority of cases in indomethacin-treated preparations. In deendothelial preparations which were induced by intraluminal administration of saponin ( 1 and $3 \mathrm{mg}$ ), the tachyphylaxis was induced similar to non-saponin treated preparations. It is concluded that 1) prostaglandin may partially participate in induction of angiotensin-induced tachyphylaxis, 2) the prostaglandin may be synthesized in the inside of vasculature, and 3) a large dose of angiotensin II induces tachyphylaxis unrelated to production of prostaglandin. — dog mesenteric artery ; cannula inserting method; angiotensin II ; indomethacin

Angiotensin-induced tachyphylaxis has been well known in isolated preparations of vascular and non-vascular smooth muscle as reviewed by Page and Bumpus (1961). Two theories were proposed on angiotensin tachyphylaxis. One postulates that it is due to the long-lasting occupancy of the angiotensin receptors by the agonist. The other theory explains tachyphylaxis as a consequence of the exhaustion of a hypothetical secondary messenger of angiotensin such as catecholamines and prostaglandins (Distler et al. 1965; Aiken 1974).

Recently, a new method (cannula inserting method) for perfusing isolated arteries was developed by Hongo and Chiba (1983) and modified by Tsuji and Chiba (1984). By use of this method, vascular responses of isolated mesenteric arteries to vasoactive substances were widely investigated (Chiba and Tsukada

Received August 22, 1986; accepted for publication November 10, 1986. 
$1984 \mathrm{a}, \mathrm{b}, \mathrm{c})$. In the present experiments, we made an attempt to study a participation of prostaglandin to angiotensin tachyphylaxis in isolated dog mesenteric arteries, using the cannula inserting method. Since intraluminal saponin injection readily destroyed the endothelium in the canine mesenteric arteries (Chiba and Tsukada 1984d, 1986), the tachyphylaxis was also examined after intraluminal saponin treatment. Because, it was reported that angiotensin II stimulated prostaglandin production in the cultured human and bovine vascular endothelium (Gimbrone and Alexander 1975; Weksler et al. 1978).

\section{Methods}

Thirty-nine mongrel dogs $(8-20 \mathrm{~kg})$ of either sex were anesthetized with sodium pentobarbital ( $30 \mathrm{mg} / \mathrm{kg}$, i.v.), and the animals were sacrificed by rapid exsanguination from the right common carotid artery after administration of sodium heparin ( 50 units $/ \mathrm{kg}$, i.v.). Arteries (which applied the middle portion of the small intestine) which are median branches of the cranial mesenteric artery were carefully isolated. Isolated arteries selected for study were $10-15 \mathrm{~mm}$ in length and $0.8-1.3 \mathrm{~mm}$ in outer diameter. A stainless steel cannula with small holes at a 2-5 $\mathrm{mm}$ distance from the distal sealed end (25-27 gauge, 0.4$0.68 \mathrm{~mm}$ in outer diameter and $3 \mathrm{~cm}$ length) was carefully inserted into each segment to avoid injury of the internal surface of the vessel as described previously (Tsuji and Chiba 1984 ; Chiba and Tsukada 1984a). The proximal part of each segment was tied to the stainless steel cannula which passed through the intraluminal surface of the isolated artery. The isolated and cannulated artery was placed in a bath which was maintained at a constant temperature of $37^{\circ} \mathrm{C}$ (Haake FE2) and was perfused with Krebs solution (millimolar composition: $\mathrm{NaCl}, 118 ; \mathrm{KCl}, 4.7 ; \mathrm{CaCl}_{2}, 2.5 ; \mathrm{KH}_{2} \mathrm{PO}_{4}, 1.2 ; \mathrm{MgCl}_{2}, 1.2 ; \mathrm{NaHCO}_{3}, 25$ and glucose, 5.6) by means of a peristaltic pump. The perfusion solution was bubbled with $95 \% \mathrm{O}_{2}$ and $5 \% \mathrm{CO}_{2}$, maintaining the $\mathrm{pH}$ levels at 7.2-7.4. The flow rate was initially adjusted so that the perfusion pressure was between $50-100 \mathrm{mmHg}$, and then it was kept constant throughout the experiment $(0.5-1.5 \mathrm{ml} / \mathrm{min})$. The constrictor response was, therefore, observed as an increase in perfusion pressure.

Drugs used in this study were $d l$-norepinephrine hydrochloride (Sankyo), phentolamine mesylate (Ciba), angiotensin II (Ciba), indomethacin (Sigma), saponin (Kanto Chem. Co.) and potassium chloride. Indomethacin was initially dissolved in $2 \%$ sodium bicarbonate, and this solution was added by saline to obtain the final concentration. Each drug solution was intraluminally administered into the perfusion line close to the cannula in a volume of 0.01-0.03 $\mathrm{ml}$ over $4 \mathrm{sec}$ by use of a microinjector (Terumo Co.).

The data were all expressed as mean \pm s.E. and evaluated statistically by Student's $t$-test for unpaired samples.

\section{Results}

\section{Angiotensin II-induced tachyphylaxis}

When angiotensin II was intraluminally administered at a dose range of $0.03-$ $0.5 \mu \mathrm{g}$, a transient increase in perfusion pressure by $50-200 \mathrm{mmHg}$ which usually lasted from 1 to $2 \mathrm{~min}$ in non-treated arterial preparations was observed. An equal dose, administered 10, 20, 30 or 60 min after the first one had been administered, consistently produced a much smaller effect. Repeated administrations caused tachyphylaxis and at shorter intervals induced more rapid tachyphylaxis. Fig. 1 shows an example of tachyphylaxis caused by repeated injections of $0.05 \mu \mathrm{g}$ 


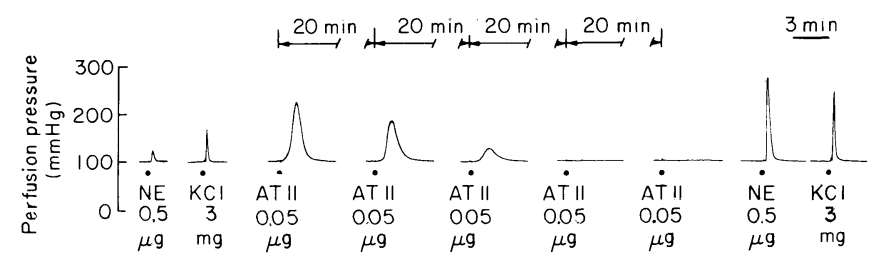

Fig. 1. Effects of $0.5 \mu \mathrm{g}$ of norepinephrine (NE), $3 \mathrm{mg}$ of potassium chloride $(\mathrm{KCl})$ and $0.05 \mu \mathrm{g}$ of angiotensin II on an isolated and perfused canine mesenteric arterial preparation. Complete tachyhylaxis was induced after three bolus injections of angiotensin II at 20-min intervals.

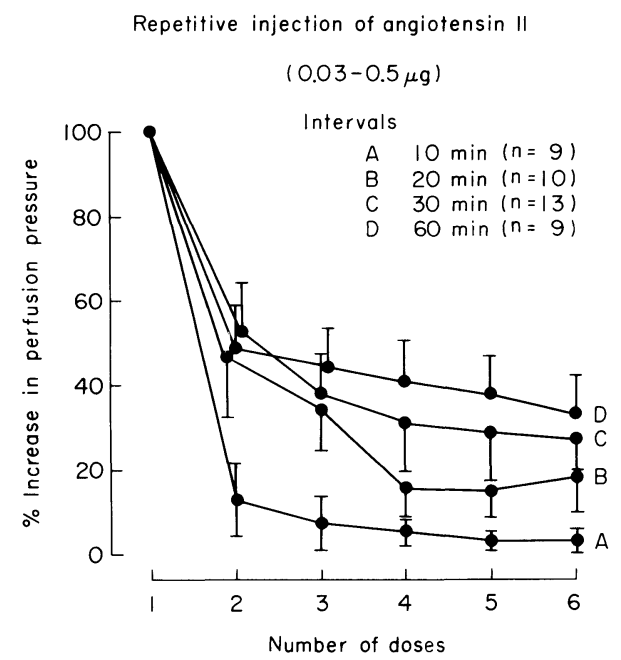

Fig. 2. Angiotensin II-induced tachyphylactic actions on isolated and perfused canine mesenteric arteries in 4 different intervals. There were no statistical differences in used doses among the experiments of 4 different intervals.

of angiotensin II at 20 min intervals. In the majority of preparations as in this figure, responses to potassium chloride or norepinephrine were enhanced after an administration of angiotensin II. In three phentolamine (10 $\mu \mathrm{g})$-treated preparations, angiotensin-induced tachyphylaxis was almost of the same patterns as in nontreated preparations. Fig. 2 shows summarized data of tachyphylaxis induced by angiotensin II in 4 different intervals. Even, at $60 \mathrm{~min}$ intervals, tachyphylaxis was usually obtained. We tried to obtain the dose-response curve for angiotensin II, but the threshold dose of angiotensin II was not obtained because of lack of the vascular response to a relatively small dose. Moreover, tachyphylaxis by angiotensin II was so marked that it was impossible to make the dose-response curve for angiotensin II in the same preparation. Thus, in the present experiments, the dose response curve for angiotensin II was not obtained. Fig. 3 shows summarized data of effects of repeated administrations of different doses of angiotensin II. Relatively large doses of angiotensin II readily produced 
Repetitive injection of angiotensin II

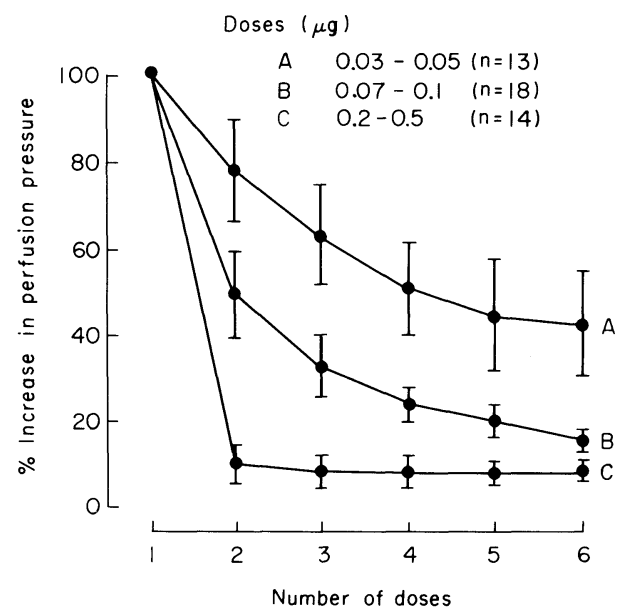

Fig. 3. Influences of different doses on angiotensin II-induced tachyphylaxis in canine isolated mesenteric arteries. Intervals of angiotensin II administration were $10-30 \mathrm{~min}$.

rapid tachyphylaxis.

\section{Effects of indomethacin treatment on angiotensin II-induced tachyphylaxis}

In this series of experiments, angiotensin II was administered after treatment with $5 \mathrm{mg}$ of indomethacin. Indomethacin $(5 \mathrm{mg})$ directly caused an increase in perfusion pressure in 7 of 16 preparations $(16 \pm 9 \mathrm{mmHg})$. After the perfusion pressure had become stable, angiotensin II was repeatedly injected. As shown in Fig. 4(A), in a non-treated preparation, $0.1 \mu \mathrm{g}$ of angiotensin II at $10 \mathrm{~min}$ intervals rapidly induced tachyphylaxis. The second dose was a much smaller effect, while the third dose was ineffective. In a preparation pretreated with $5 \mathrm{mg}$ of
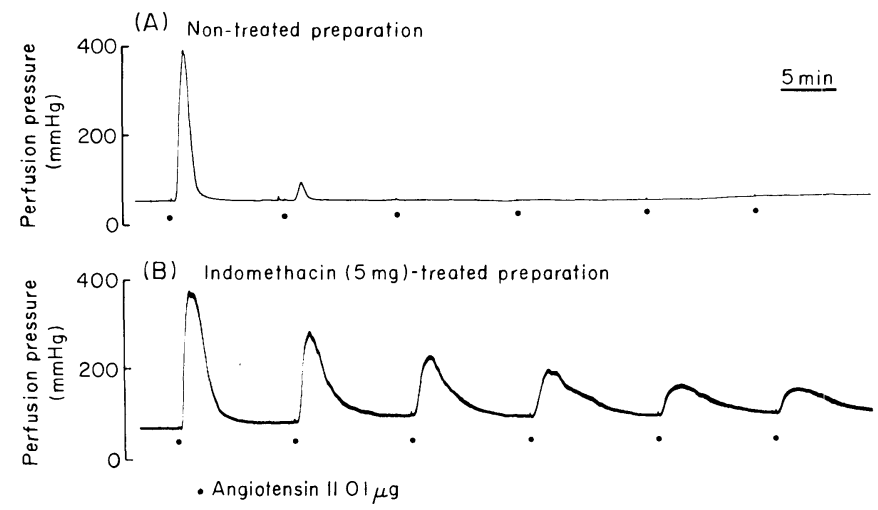

Fig. 4. Tracings of repetitive injections of $0.1 \mu \mathrm{g}$ of angiotensin II on non-treated

(A) and indomethacin (5 mg)-treated (B) preparations at 10-min intervals. 
Repetitive injection of angiotensin II (10 min intervals)

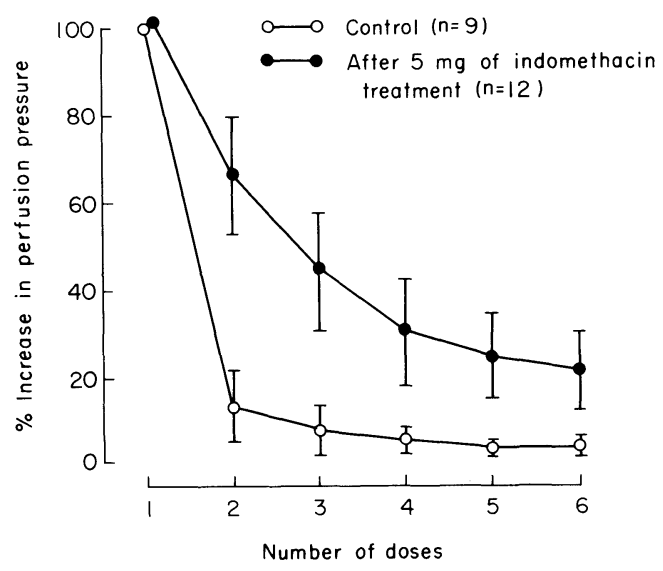

Fig. 5. Effects of pretreatment with $5 \mathrm{mg}$ of indomethacin on repetitive injections of angiotensin II at 10-min intervals in isolated mesenteric arteries. Used doses of angiotensin II in two groups of experiments were not statistically different (Control doses of angiotensin II, $0.15 \pm 0.06 \mu \mathrm{g}$; angiotensin II in indomethacin-treated preparations, $0.12 \pm 0.03 \mu \mathrm{g}$ ).

Repetitive injection of angiotensin II

Indomethacin (5 mg)-treated preparations
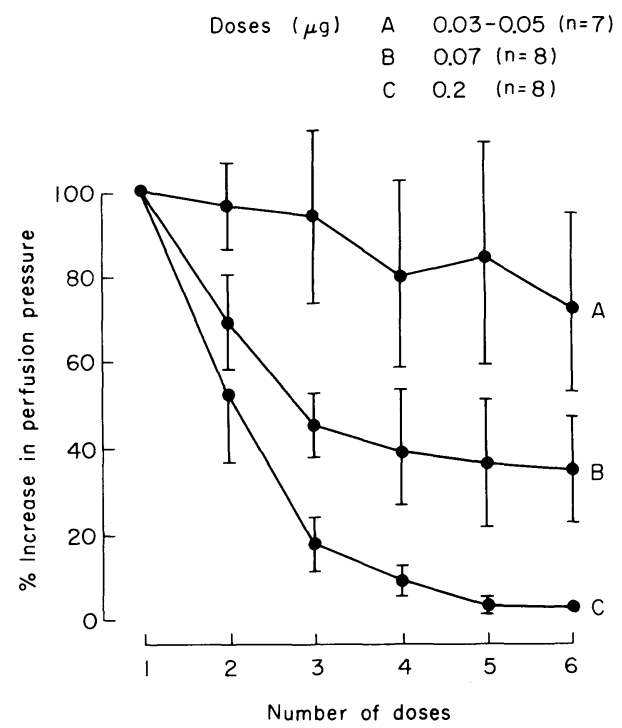

Fig. 6. Effects of $5 \mathrm{mg}$ of indomethacin on angiotensin II-induced tachyphylaxis. Intervals of angiotensin II administration were $10-30 \mathrm{~min}$. No significant differences are obtained in each point of $\mathrm{A}$ line. 


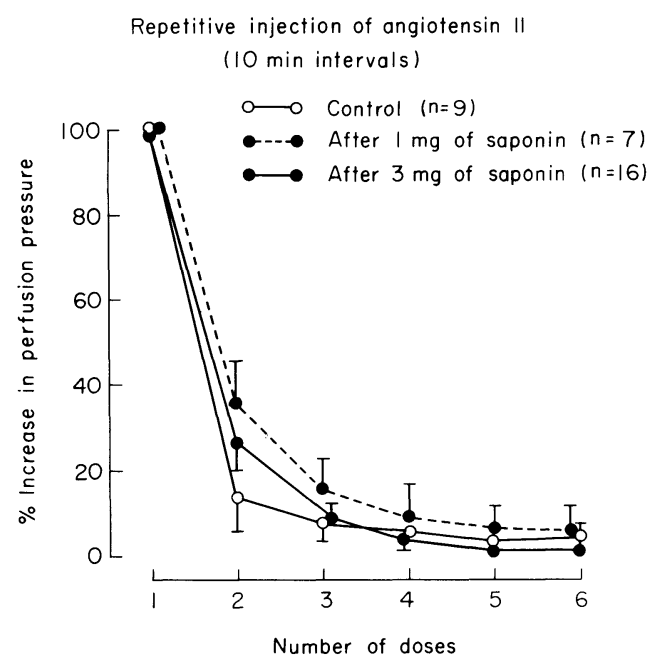

Fig. 7. Effects of pretreatment of canine mesenteric arteries with 1 and $3 \mathrm{mg}$ of intraluminal saponin on angiotensin II-induced tachyphylaxis at 10-min intervals. No statistic differences were obtained in three group experiments (Control doses of angiotensin II, $0.15 \pm 0.06 \mu \mathrm{g}$; angiotensin II in $1 \mathrm{mg}$ saponintreated preparations, $0.10 \pm 0.03 \mu \mathrm{g}$; angiotensin II in $3 \mathrm{mg}$ saponin-treated preparations, $0.17 \pm 0.04 \mu \mathrm{g}$.

indomethacin, angiotensin II-induced tachyphylaxis was not so distinguished and the period of action of vasoconstriction usually prolonged much longer than $5 \mathrm{~min}$ as shown in Fig. 4(B). Summarized data are shown in Fig. 5.

When a relatively small dose of angiotensin II was given in indomethacintreated preparations, tachyphylaxis was not clear in the majority of cases, but a large doses of angiotensin II induced a definite tachyphylaxis even in indomethacin-treated preparations as shown in Fig. 6.

\section{Effects of repetitive injections of angiotension II on saponin-treated preparations}

When saponin was intraluminally administered in a dose of 1 and $3 \mathrm{mg}$, the endothelium was mostly removed as reported previously (Chiba and Tsukada 1984d ; 1986). Saponin-treatment frequently caused a slight transient increase in perfusion pressure. It became stable 10-30 min latter at usually sligiht higher level $(5-20 \mathrm{mmHg})$ of perfusion pressure. In saponin-treated preparations, angiotensin II produced tachyphylaxis as well as control preparations. Summarized data are shown in Fig. 7.

\section{Discussion}

In the present experiments, we used isolated and perfused canine mesenteric arterial preparations and confirmed angiotensin tachyphylaxis which has been reported in vascular preparations (Page and Bumpus 1961 ; Palaic and Lemorvan 
1971 ; Stwart 1974; Fasciolo and Binia 1981; Webb 1982 ; Oshiro et al. 1984). In 1974, Aiken suggested that mechanism of tachyphylaxis to angiotensin II might be related to the production of prostaglandins by the tissue. He considered that angiotensin II induced prostaglandin production and the prostaglandins formed exert an inhibitory action that attenuates the contractile action of angiotensin II, observing that inhibitors of prostaglandin synthesis reversed tachyphylaxis to angiotensin II in rabbit celiac and mesenteric arteries.

In the present study, we demonstrated that angiotensin tachyphylaxis was significantly extinguished in indomethacin-treated preparations, especially at a relatively small dose level of angiotensin II. Thus, a small dose level of angiotensin II which still has strong vasoconstrictor action may induced tachyphylactic effects induced by a release of vasodilatory prostaglandin like prostacyclin. It was suggested that prostacyclin synthesis was performed in vascular endothelial cells (Moncada et al. 1977 ; Eldor et al. 1981 ; De Mey et al. 1982), and in cultured human and bovine endothelial cells (Gimbrone and Alexander 1975; Weksler et al. 1978). Immunometric studies showed that concentrations of prostacyclin synthetase are equal in endothelial and smooth muscle cells of bovine aorta, but that the concentration of cyclooxygenase in 2-fold higher in the endothelial than in the smooth muscle (De Witt et al. 1983; Smith et al. 1983). Goldsmith (1982) reported that the release of prostacyclin at the luminal surface of the bovine aorta was initially increased after in vitro removal of the endothelium. Later the denuded regions of vessels had blunted 6-keto-prostaglandin $\mathrm{F}_{2 \alpha}$ release under basal and stimulated conditions equal to $5 \%$ to $25 \%$ of that obtained adjacent intact regions. More recently, Boeynaems et al. (1985) reported that endothelium removal produced an immediate prostacyclin release, amounting to $408 \%$ of the control after rubbing, during the first 30-min period of incubation by use of the isolated rabbit aorta. In the present study, we tried effects of angiotensin II on de-endothelial preparations induced by intraluminal saponin. However, there were no differences of angiotensin tachyphylaxis between saponin-treated and non-treated preparations, indicating that the endothelium does not influence the prostaglandin synthesis by angiotensin II. It is reported that isolated and perfused rabbit mesenteric blood vessels sellectively metabolized arachidonic acid to prostacyclin (Pure and Needleman 1979). Moreover, they showed that denuding the blood vessels of their endothelial layer by perfusion with hypotonic fluid did not affect the metabolism of arachidonic acid or the response to peptide stimulation, suggesting that prostacyclin synthetase and angiotensin II receptors are present in the subendothelial smooth muscle cells of the vessel walls. Vascular smooth muscle cell cultures have also been shown to be capable of synthesizing prostacyclin from arachidonic acid (Baenziger et al. 1977). In 1983, Ody et al. failed to elicit any specific prostaglandin secretion and to detect specific angiotensin receptors at the surface of intact cultured endothelial cells.

In this study, we used the cannula inserting method (Hongo and Chiba 1983 ; 
Tsuji and Chiba 1984), and carefully inserted a cannula to the isolated artery. Although we reported the intact endothelium in the results of morphological examinations in used mesenteric and basilar arteries (Chiba and Tsukada 1986 ; Chiba et al. 1986), it was not ruled out completely whether endothelial function is influenced by inserting of the cannula. However, since it was already reported that the endothelium was completely rubbed after treatment with intraluminal saponin (Chiba and Tsukada 1986; Chiba et al. 1986), it was considered that the endothelium has no significant production of prostaglandins in this relatively large artery. In the present study, at larger doses, angiotensin II tachyphylaxis was not modified by treatment with indomethacin. In 1965, Distler et al. reported that angiotensin II induced a release of norepinephrine from the sympathetic nerves in isolated blood vessels. However, in the present study, used doses of angiotensin II did not show any evidence of catecholamine release. Because phentolamine treatment did not modify the angiotensin II-induced tachyphylaxis. The mechanism of tachyphylaxis to angiotensin II in vascular smooth muscle is presumed to be related to receptor occupancy (Bohr 1973). The angiotensin II molecule occupies the receptor site and thereby prevents its activation by subsequent exposures to the drug. Palaic and Lemorvan (1971), using tritiated angiotensin II, tried to find out whether the receptor sites for angiotensin II were reduced during tachyphylaxis. However, their conclusion was that receptor sites increased during tachyphylaxis. Fasciolo and Binia (1981) showed to be able to induce tachyphylaxis without any vascular effect of the angiotensin by perfusing the rat mesenteric preparation with diluted angiotensin solutions. Khairallah et al. (1966) proposed that tachyphylaxis may be due to strong binding of angiotensin to its receptors resulting in slow dissociation of the hormonereceptor complex. Further more, it was suggested that there is a correlation between the receptor affinity of different analogs and their ability to produce tachyphylaxis (Moore and Khairallah 1976). Moreover, it must be considered that receptor sites may be altered by angiotensin II treatment. In the present experiments, norepinephrineand potassium chloride- induced vasoconstrictions were consistently potentiated by angiotensin II. We used these 2 substances to confirm whether vascular reactivity was intact or not. We have no idea to prove whether these potentiation mechanisms have a relationship to angiotension tachyphylaxis.

From these results, it is considered that angiotensin II may produce tachyphylactic actions in 2 different mechanisms, i.e., 1) a release of prostaglandins from vascular smooth muscle, and 2) the receptor occupation, and in small doses the former distinctly appears and in large doses the latter becomes clear.

\section{References}

1) Aiken, J.W. (1974) Effect of prostaglandin synthesis inhibitors on angiotensin tachyphylaxis in the isolated coeliac and mesenteric arteries of the rabbit. Pol. $J$. Pharmacol. Pharma., 26, 217-227. 
2) Baenziger, N.L., Dillender, M.J. \& Majerus, P.W. (1977) Culture human skin fibroblasts and arterial cells produce a labile platelet-inhibitory prostaglandin. Biochem. biophys. Res. Commun., 78, 294-301.

3) Boeynaems, J.M., Galand, N. \& Ketelbant, P. (1985) Prostacyclin production by the deendothelialized rabbit aorta. J. clin. Invest., 76, 7-14.

4) Bohr, D.F. (1973) Angiotensin on vascular smooth muscle. In: Handbook of Experimental Pharmacology, vol. 37, edited by I.H. Page \& F.M. Bumpus, Springer, Berlin, pp. 424-440.

5) Chiba, S. \& Tsukada, M. (1984a) Vasoconstrictor responses of isolated and perfused canine mesenteric arteries to alpha-adrenoceptor agonists. Arch. int. Pharmacodyn., 271, 241-248.

6) Chiba, S. \& Tsukada, M. (1984b) Effect of $\mathrm{pH}$ alterations on the vascular reactivity of dog isolated perfused mesenteric arteries. Jap. J. Pharmacol., 34, 465-467.

7) Chiba, S. \& Tsukada, M. (1984c) Comparison of the vascular responses of simian and canine mesenteric arteries to vasoactive subastances. Jap. J. Pharmacol., 35, 199201.

8) Chiba, S. \& Tsukada, M. (1984d) Vasoconstrictor responses induced by $\alpha$ adrenoceptor agonists before and after removal of the endothelial cells of dog mesenteric arteries. J. auton. Pharmacol., 4, 257-260.

9) Chiba, S. \& Tsukada, M. (1986) Comparison of vasoconstrictor actions of norepinephrine and potassium chloride before and after damage of endothelium by saponin. Heart and Vessels, 2, 1-5.

10) Chiba, S., Itoh, N. \& Tsuji, T. (1986) Vascular responses to intraluminal acetylcholine in isolated, perfused canine simian basilar arteries. J. auton. Pharmacol., 6, 101-107.

11) De Mey, J.G., Claeys, M. \& Vanhoutte, P.M. (1982) Endothelium-dependent inhibitory effects of acetylcholine, adenosine triphosphate, thrombin and arachidonic acid in the canine femoral artery. J. Pharmacol. exp. Ther., 222, 166-173.

12) De Witt, D.L., Day, J.S., Sonnenburg, W.K. \& Smith, W.L. (1983) Concentrations of prostaglandin endoperoxide synthase and prostaglandin $\mathrm{I}_{2}$ synthase in the endothelium and smooth muscle of bovine aorta. J . clin. Invest., 72, 1881-1888.

13) Distler, A., Libau, H. \& Wolff, H.P. (1965) Action of angiotensin on sympathetic nerve endings in isolated blood vessels. Nature (Lond.), 206, 764-765.

14) Eldor, A., Falcone, D.J., Hajjar, D.P., Minick, C.R. \& Weksler, B.B. (1981) Recovery of prostaglandin production by deendothelialized rabbit aorta. $J$. clin. Invest., 67, $735-741$.

15) Fasciolo, J.C. \& Binia, A. (1981) Angiotensin I, II, and III tachyphylaxis in the mesenteric vascular circuit of the rat. Hypertension, 3, Suppl. II, II-166-170.

16) Gimbrone, M.A., Jr. \& Alexander, R.T. (1975) Angiotensin II stimulation of prostaglandin production in cultured human vascular endothelium. Science, 189, 219-220.

17) Goldsmith, J.C. (1982) Contribution of the subendothelium to prostacyclin release after vascular injury. J. Lab. clin. Med., 100, 574-584.

18) Hongo, K. \& Chiba, S. (1983) A new method for measuring vascular responsiveness of relatively larger arteries of dogs. J. pharmacol. Methods, 9, 83-91.

19) Khairallah, P.A., Page, I.H., Bumpus, F.M. \& Turker, R.K. (1966) Angiotensin tachyphylaxis and its reversal. Circulat. Res., 19, 247-254.

20) Moncada, S., Herman, A.G., Higgs, E.A. \& Vane, J.R. (1977) Differential formation of prostacyclin (PGX or $\mathrm{PGI}_{2}$ ) by layers of the arterial wall. An explanation for the antithrombolic properties of vascular endothelium. Thrombos. Res., 11, 323-344.

21) Moore, A. \& Khairallah, P.A. (1976) Further studies on angiotensin tachyphylaxis. J. Pharmacol. exp. Ther., 197, 575-581.

22) Ody, C., Seillan, C., Russo-Marie, F. \& Duval, D. (1983) Angiotensin II does not elicit any specific prostaglandin secretion in piglet cultured endothelial cells. Throm- 
bos. Res., 31, 219-231.

23) Oshiro, M.E.M., Miasiro, N., Paiva, T.B. \& Paiva, A.C.M. (1984) Angiotensin tachyphylaxis in the isolated rabbit aorta. Blood Vessels, 21, 72-79.

24) Page, I.H. \& Bumpus, M. (1961) Angiotensin. Physiol. Rev., 41, 331-390.

25) Palaic, D. \& Lemorvan, P. (1971) Angiotensin tachyphylaxis in guinea-pig aortic strips. J. Pharmacol. exp. Ther., 179, 522-531.

26) Pure, E. \& Needleman, P. (1979) Effect of endothelial damage on prostaglandin synthesis by isolated perfused rabbit mesenteric vasculature. J. cardiovasc. Pharmacol., 1, 299-309.

27) Smith, W.L., De Witt, D.L. \& Allen, M.L. (1983) Bimodal distribution of the PGI syntase antigen in smooth muscle cells. J. biol. Chem., 258, 5922-5926.

28) Stwart, J.M. (1974) Tachyphylaxis to angiotensin. In : Angiotensin, edited by I.H. Page \& F.M. Bumpus, Springer, Berlin, pp. 170-184.

29) Tsuji, T. \& Chiba, S. (1984) Potentiating effect of methysergide on norepinephrineinduced constriction of the isolated internal carotid artery of the dog. Jap. J. Pharmacol., 34, 95-100.

30) Webb, R.C. (1982) Angiotensin II-induced relaxation of vascular smooth muscle. Blood Vessels, 19, 165-176.

31) Weksler, B.B., Marcus, A.J. \& Jaffe, E.A. (1978) Synthesis of prostaglandin $I_{2}$ (prostacyclin) by cultured human and bovine endothelial cells. Proc. nat. Acad. Sci. USA, 74, 3922-3926. 